\title{
An Intelligent Tool Selection System Based on CRB and RBR
}

\author{
Rui Wang, Wu Zhao", Cunjing Luo, Zhiyong Wang, Tao Luo
}

School of Manufacturing Science and Engineering, Sichuan University, Chengdu Sichuan Province First Ring Road, No. 24, 610065, China

\begin{abstract}
The manufacturing industries dealing with machining and tools' manufacturing generate a large amount of data concerning the machining process. However, in most cases, this information is not used efficiently as there is no system dedicated for storing and manipulating such data. In order to use these data to improve the efficiency and increase the benefit of machining, the cutting database system is built for these manufacturing enterprises, which can provide rational cutting parameters and tool solutions. JAVA and MYSQL are used as the base of database management system, combining XML and JavaScript technology. The intelligent tool selection model was designed, and the functions of basic information management and query were realized. It was concluded that it can commend reasonable cutting parameters and tool solutions according to machining condition input.
\end{abstract}

Keywords: Intelligent, Machining, Tool selection, RBR, CDS, Geometric parameters.

\section{INTRODUCTION}

Over the past few years, the specifications of the structure and objective of tool selection and management procedures have become important considerations in modern enterprises [1]. The integration of tool and cutting parameters selection techniques for manufacturing, process planning and tool management is the most urgent trend, as the traditional way, which uses the expertise of the machining operator to determine the correct tool, is no longer fit for the development of enterprise for following reasons [2].

a) More types of tools and more complex tasks of processing have made the task of determining the correct tool too complicated to be left to the machine operator.

b) If the issue of tool selection is left to the operator, machines stoppages due to the incorrect use or unavailability of tools, become inevitable.

c) Due to the high cost of cutting tools, it is no longer economical to allow tools to be kept as individual machine tools when they are not in use.

d) In the twenty-first century, there has been an irreconcilable contradiction between highly intelligent enterprise production and tool selection which is dependent on the experience of workers.

The process of selecting cutting tools and deciding the associated cutting conditions is an important part of the detailed process of planning activity for machining [3-6]. Moreover, it is complex to provide rational cutting parameters, tool and solutions, which require the development of

*Address correspondence to this author at the School of Manufacturing Science and Engineering, Sichuan University, Chengdu Sichuan Province First Ring Road, No. 24, 610065, China; E-mail: zhaowuedu@163.com sophisticated programs that should be supported by databases containing information on the manufacturing resources and company-specific machining process. Modern enterprises which seek to reduce the cost and improve the production efficiency have to realize scientific and rational management of tool and reasonable selection of cutting tool and cutting parameter [7]. Therefore, a Cutting Database System was designed and implemented for these enterprises to solve the complex task.

This paper proposed an intelligent tool selection model. Through this general model, a cutting database system which applied for tool selection and management was established.

\section{INTELLIGENT TOOL SELECTION MODEL}

Usually, the whole process of cutting tool selection is very complex, as there are many aspects and problems to be considered. Different processing conditions, different processing characteristics and different machining precision directly influence the tool selection which makes the acquisition of tool selection knowledge more difficult. In recent years there are two mainstream methods: Rule based reasoning (RBR) and Case based reasoning (CBR). Many papers studied RBR and CBR for their advantages and disadvantages, therefore, this paper will not elaborate these aspects. The intelligent tool selection model was established by combining RBR and CBR in this paper, as shown in Fig. (1).

In this paper, the cutting tool selection task was divided into two plates and each plate had its own method to solve problem, according to the features. Division of the cutting tool selection task not only obtains the corresponding division, but also makes the knowledge reasoning and knowledge acquisition simple. As can be seen from the Fig. (1), intelligent tool selection is divided into two sub tasks as follows: 


\section{The intelligent tool selection model}

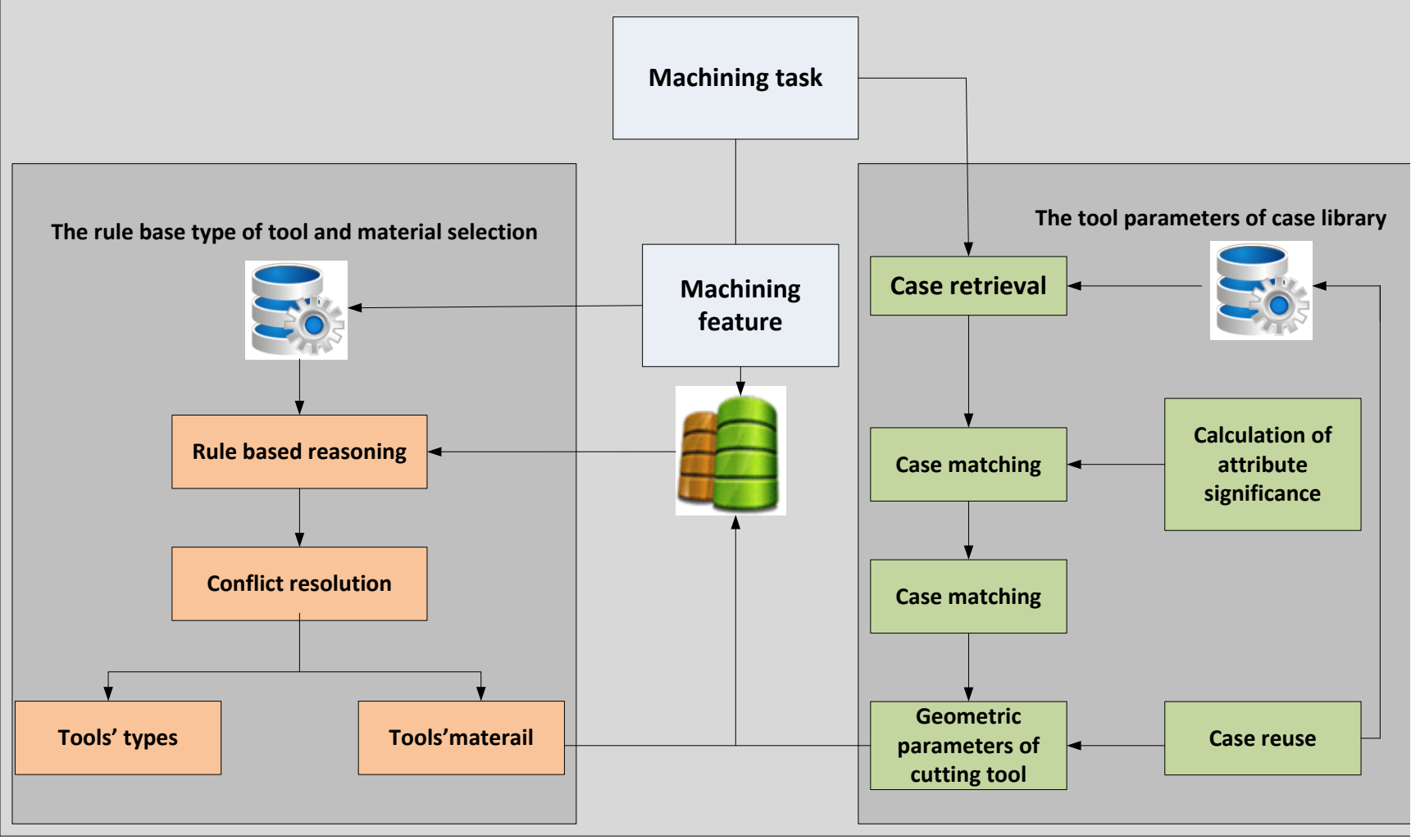

Fig. (1). The intelligent tool selection model.

(1) Confirmation of the types of cutting tools and cutting tool materials: The types of cutting tools and cutting tool materials are confirmed through RBR. The knowledge form of the types of cutting tools and cutting tool materials is relatively clear, and it is easy to summarize the rules. It can not only realize convenient retrieval by using hierarchical storage mode in rule base, but also rule matching in RBR is easier than retrieval in CBR. The conclusion obtained can be directly used as the initial inputs for case retrieval.

(2) Confirmation of the geometric parameters of cutting tool: The geometric parameters of cutting tool are confirmed through CBR. The influence factors of geometric parameters of cutting tool selection are relatively large, therefore, some schemes cannot be determined directly with RBR. At the same time selection rules are difficult to summarize. Normally the operating personnel take assistance from the memories of the past, and focus on the comparison, and analysis of the present problem, and subsequently, come up with solutions to new problems. This way which make computer analog to human thinking activity is CBR. Therefore, CBR was chosen to select he geometric parameters of cutting tool.

\subsection{Tool Type and Material Selection Based on RBR}

Before determining the geometry parameter of the tool, the cutting tool types and materials need to be determined. There are many kinds of tool types. According to the machining feature, different tools can be classified, and the type of tool is mainly selected depending on the workpiece machining properties (roughing, semi finishing and finishing) and workpiece machining feature information. Moreover, tool material selection depends on the workpiece machining properties and the workpiece material. Tool materials for each species have the best matching processing object, and the target of cutting tool materials and processing objects mainly refers to the mechanical properties, physical properties and chemical properties of phase matching, in order to obtain the largest cutting productivity and the longest tool life. For each of the processing object, the workpiece material, machining properties and machining feature should be assessed to determine the type and material of tool. In this paper, the improved production rule method was used to achieve specific rule reasoning production, as shown in Fig. (2).

RBR is realized by a group of degree, which is responsible for search, matching and storage rules. The specific process of tool type and material selection is as follows: 


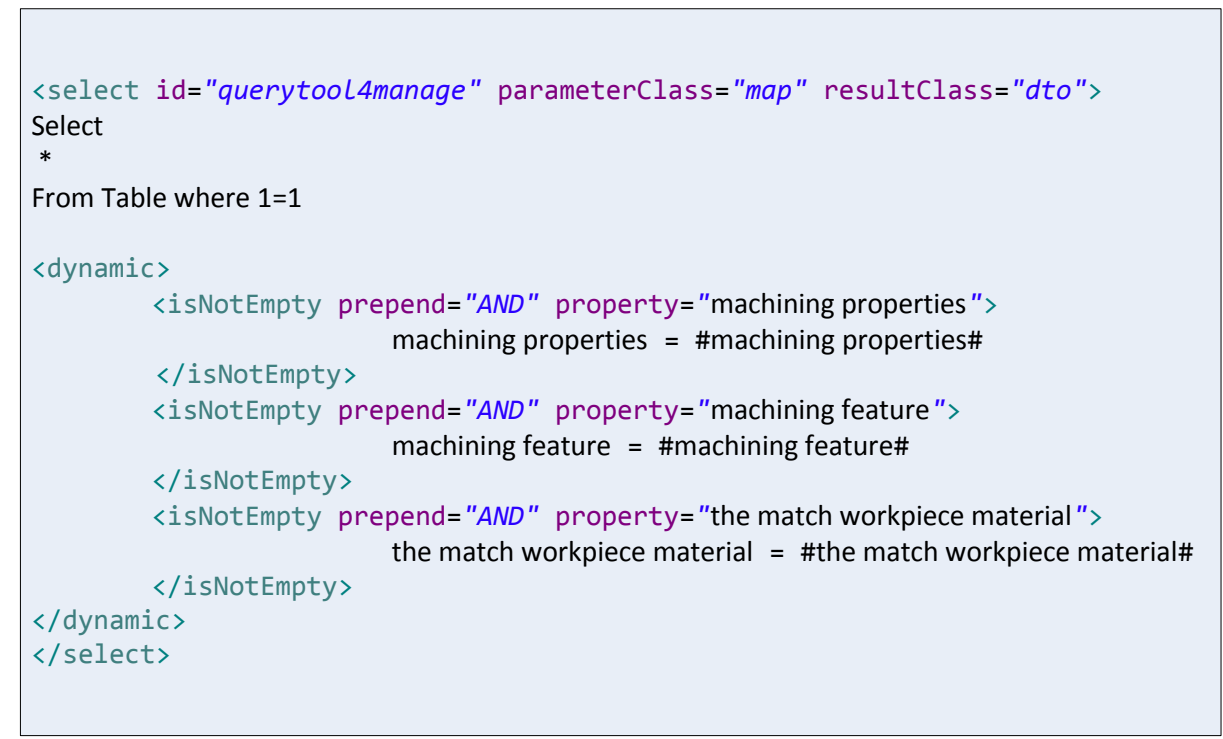

Fig. (2). the improved production rule method.

(1) Identifying the workpiece material, machining properties and machining feature as the initial condition and the basis for solving problems

(2) Through the dynamic selection, the input values are matched with the values in the database, and the corresponding tool set is selected.

\subsection{The Selection of Geometric Parameters of Cutting Tool Based on CBR}

In general, the system based on CBR has 4 steps: case retrieval, case matching, case rewriting and case storage inference step. The basic principle is that the past experience is stored as a case, and when faced with a new problem, it can be searched from the case database to find the right case as the reference, and this is actually achieved as experience reuse. If there is a complaint about the case, it can be modified to adapt to the current situation. The modified case is again stored in the case base, as a reference for next time, which is actually a self-learning implementation experience. The most important case based on reasoning technology support is the case base, and its key technology is the expression, extraction and modification of cases.

(1) Establishment of the case base. The main feature of tool geometric parameters includes the workpiece material, hardness of workpiece and machining properties, process system's rigidity, type of tool, machining environment etc. Different features play different roles in the case matching process, therefore, each feature is given different weights to reflect its importance. For this purpose, a multidimensional array was used to express the case as follows:

$$
C=[N, A, W, T, X]
$$

Here, $\mathrm{N}$ is the case identifier; $\mathrm{A}$ is the attribute features, and $A=[a 1, a 2, a 3, \ldots] ; W$ represents the weight of each at-

\begin{tabular}{|c|c|c|}
\hline \multirow{2}{*}{ Case number $\mathrm{N}$} & $\mathrm{N}$ & $\mathrm{N}$ \\
\hline & Workpiece material & Workpiece hardness \\
\hline \multirow{2}{*}{ Case name } & W & W \\
\hline & $\cdots \cdots$ & $\ldots \ldots$ \\
\hline \multicolumn{3}{|l|}{ confidence level } \\
\hline \multicolumn{3}{|l|}{ Workpiece material } \\
\hline \multicolumn{3}{|l|}{ Workpiece hardness } \\
\hline \multirow{2}{*}{ Maching properties } & & $\mathrm{N}$ \\
\hline & & Maching properties \\
\hline \multirow{2}{*}{$\cdots \cdots$} & & W \\
\hline & & $\ldots \ldots$ \\
\hline
\end{tabular}

Fig. (3). The case base. 
Table 1. Value of judgment matrix.

\begin{tabular}{|c|c|c|}
\hline Intensity & Intensity & Explanation \\
\hline \hline 1 & Equal & Two activities contribute equally to the object \\
\hline 3 & Moderate & Two activities contribute equally to the object \\
\hline 5 & Strong & Two activities contribute equally to the object \\
\hline 7 & Strong & Dominance of the demonstrated in practice \\
\hline 9 & Extreme & Evidence favoring one over another of highest possible order of affirmation \\
\hline $2,4,6,8$ & Intermediate & When compromise is needed \\
\hline Reciprocals of the above numbers & & For inverse comparison \\
\hline
\end{tabular}

Table 2. Random index.

\begin{tabular}{|c|c|c|c|c|c|c|}
\hline $\mathbf{n}$ & 1 & 2 & 3 & 4 & 5 & $\ldots$ \\
\hline $\mathbf{R}_{\mathbf{I}}$ & 0 & 0 & 0.52 & 0.89 & 1.12 & $\ldots$ \\
\hline
\end{tabular}

tribute feature, and $\mathrm{W}=[\mathrm{w} 1, \mathrm{w} 2, \mathrm{w} 3, \ldots] ; \mathrm{T}$ is the solution; and $\mathrm{X}$ is the confidence level set of case feature. The case base was established, as shown in Fig. (3).

(2) The weight of each attribute feature was calculated. The weight of each attribute feature can be obtained by AHP, with the judgment matrix as follows:

$$
Y=(a i j) n \times n, a i j=\mathbf{1} / \boldsymbol{a}_{j i}
$$

Here, aij stands for the comparison between the indicator $\mathrm{i}$ and $\mathrm{j}$, of which the meaning is shown in Table $\mathbf{1}$.

The consistency of the matrix was checked to guarantee that the decision makers' judgments are consistent. The Consistency Ratio CR is the indicator to measure the consistency of the judgment matrix. CR is calculated by the following formula:

$$
C I=(\lambda \max -n) /(n-1)
$$

Here, $\lambda \max$ is the maximum eigenvalue of the matrix and $\mathrm{n}$ is the order of the matrix. RI is the Random Index, which depends on $\mathrm{n}$, as shown in Table 2 . When $\mathrm{CR}<0.1$, the judgment matrix is accepted. Otherwise, the judgment matrix is revised.

Indicators are ranked in single hierarchy. Eigenvalue Method was used to obtain the weight vectors by the following formula:

$C W=\lambda W$

Here, $\lambda$ is one of the eigenvalues of the matrix and $\mathrm{W}$ is the eigenvectors corresponding to the eigenvalues $n$, which is also the weights' vector.

(3) The confidence level between new case and each case was calculated. The feature distance of ai between N0 and Ni was calculated by the following formula:
$\operatorname{Di}(N O, N i)=\left|\boldsymbol{v}_{\mathbf{0 i}}-\boldsymbol{v}_{\boldsymbol{i} \boldsymbol{i}}\right|$

Here, v0i and v1i are feature value after normalization processing, and Di is the feature distance of feature $\mathrm{i}$.

The total feature distance of ai between N0 and N1 was calculated by the following formula:

$D(N 0, N i)=\sum_{i=\mathbf{1}}^{\boldsymbol{k}} \boldsymbol{w}_{\boldsymbol{i}} \boldsymbol{D}_{\boldsymbol{i}}\left(\boldsymbol{v}_{\mathbf{0 i}}-\boldsymbol{v}_{\boldsymbol{i} i}\right)$

Here, wi is the weight of each attribute feature. The confidence level wascalculated by the following formula:

$\operatorname{Sim}(N 0, N i)=1-\boldsymbol{L} \sqrt{\boldsymbol{D}\left(\boldsymbol{N}_{\mathbf{0}}, \boldsymbol{N}_{\boldsymbol{i}}\right)}$

Here, Sim $(\mathrm{N} 0, \mathrm{Ni})$ is the confidence level between case $\mathrm{N} 0$ and $\mathrm{Ni}, \mathrm{L}$ and $\alpha$ vary from situation to situation, generally $\mathrm{L}=1$ and $\alpha=0.5$.

When the confidence level is higher, the case is closer to new case. The system will recommend the case to solve the new problem.

\section{IMPLEMENTATION OF CUTTING DATABASE SYSTEM}

The cutting database system (CDS) is the key attribute of the presented intelligent reasoning model -computer support tool. It is a convergent platform for tool matching theory, information technology and management technology. Meanwhile, it is also a platform for computer-aided tool selection, solutions and cutting parameters. Its major elements are database, the object-oriented development technology [8], and algorithmic tool selection techniques [9]. The key function of the CDS is to offer a useful platform for the administration of tools management, the machine operator in tool and cutting parameters selection, to promote the creativity of the machine operator to find new tool solutions, instead of giving up to the human wisdom to realize complete automation. 


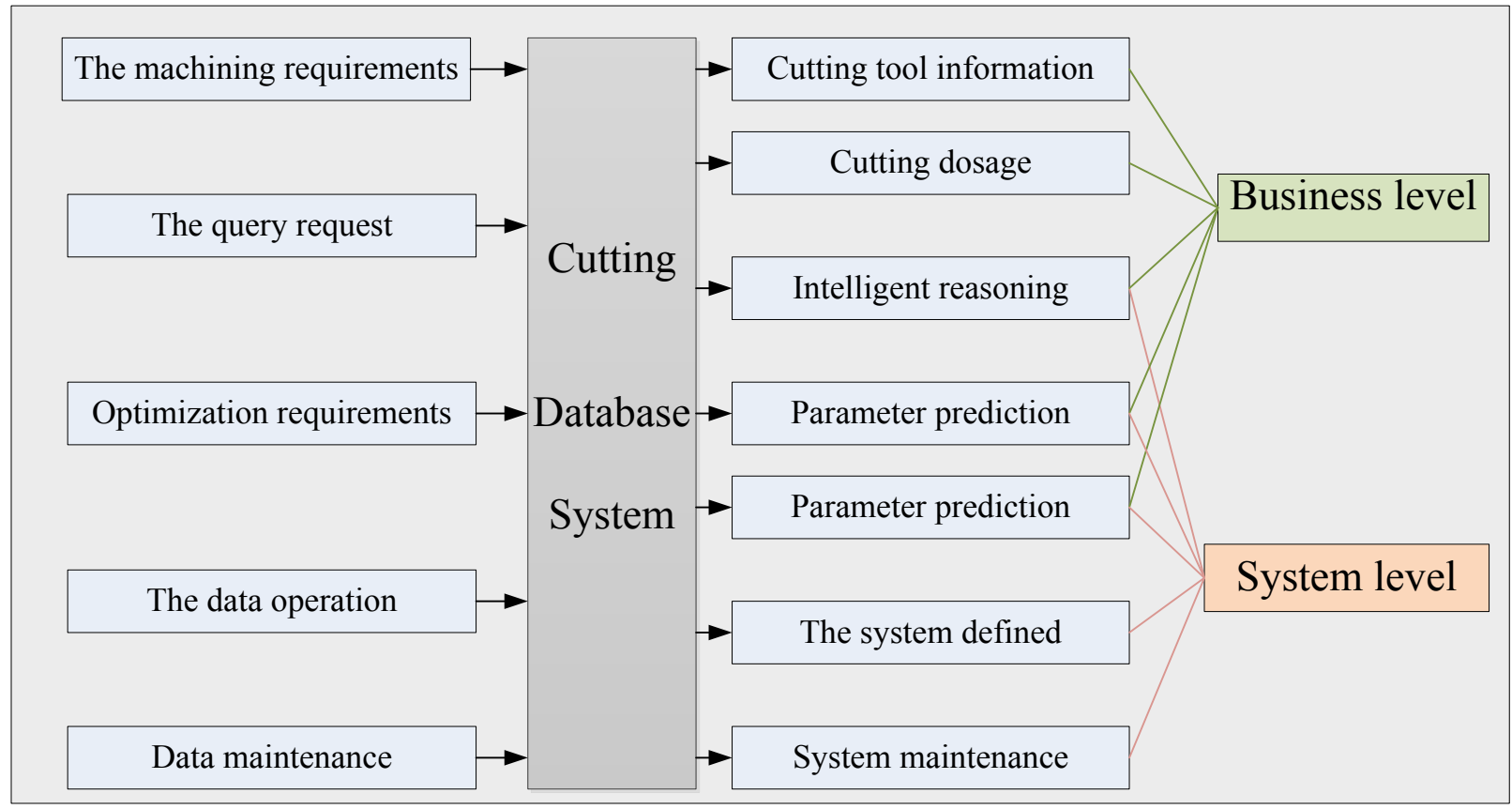

Fig. (4). The system function model.

\subsection{Function Description of System}

Through functional requirement, the system function model is established, as shown in Fig. (4). From the function point of view, system can be clustered into 5 groups:

Function menu, the role of authority, operational monitoring, data management and system help.

a) Function menu: Function modules include turning system management module, milling system management module and hole processing system management module. It also included implementation of the function such as the tool recommendation, cutting parameters recommendation, process parameter prediction and intelligent reasoning function.

b) The role of authority: Common designers and system administrator are granted different authorities based on their identities $[10,11]$, therefore, the security of system can be ensured. System administrator has the authority of managing system resources.

c) Operation monitoring: By using system operation as the basic function of the system, the user can set the system, operation monitoring, system privilege and personal settings.

d) Data management: Data management includes tool storage management, cutting tool parameters storage management, tool matching knowledge storage management and system related documents storage management. It also includes effective scientific management and organization of the tool related data through the data management.

e) System Help: This function deals with matching theory introduction, software user manual and menu management. Matching theory dealt by the system and the way of using the system are described by text, charts, cartoons, multi-media, instances and any combination of them.

\subsection{Flowchart of System}

The flowchart of System is illustrated in Fig. (5). It starts from user login and ends at user exit. Different authorities are granted based on the users' identities. System administrator is responsible for the management of function menu, the role of authority, operation monitoring, data management and system help. It would be specially mentioned that all these public knowledge resources are available in knowledge database to help operation staff generate creative solutions.

\subsection{The Interface of CDS}

According to the requirement and overall scheme design, a prototype system has been developed by using technologies such as Java, MyEclipse, XML, MYSQL and JavaScript. The key functional modules of the prototype system are shown in Fig. (6).

\section{AN APPLICATION EXAMPLE OF CDS}

A shaft was needed to be processed, with the workpiece material being 45 steel. According to the customer's demand, the outer circle's original diameter was changed from $\Phi 25$ to $\Phi 23$, to meet the assembly requirements after changes in the design. This processing task was assigned to the field operation personnel A. Following this, A logged in to CTDS, and entered the working interface. According to his knowledge and experience, A assessed that it was a task of turning type. Therefore, A opened the turning working interfaces, as shown in Fig. (7).

According to the selection process, firstly A chose 45 steel as the workpiece material. Secondly, A chose fine finishing as processing method. Following this, A chosen $\mathrm{C}$ 


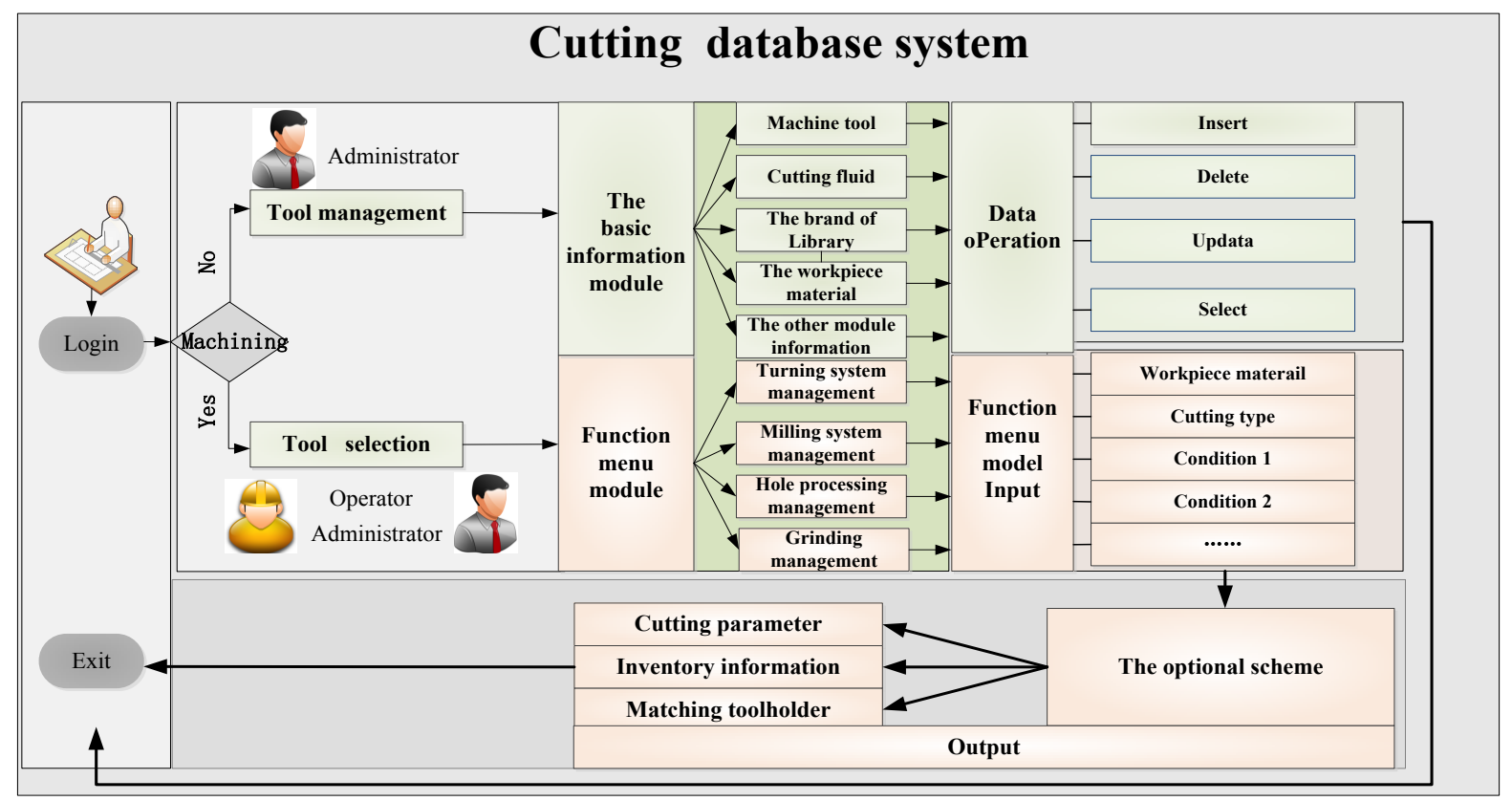

Fig. (5). The flowchart of system.

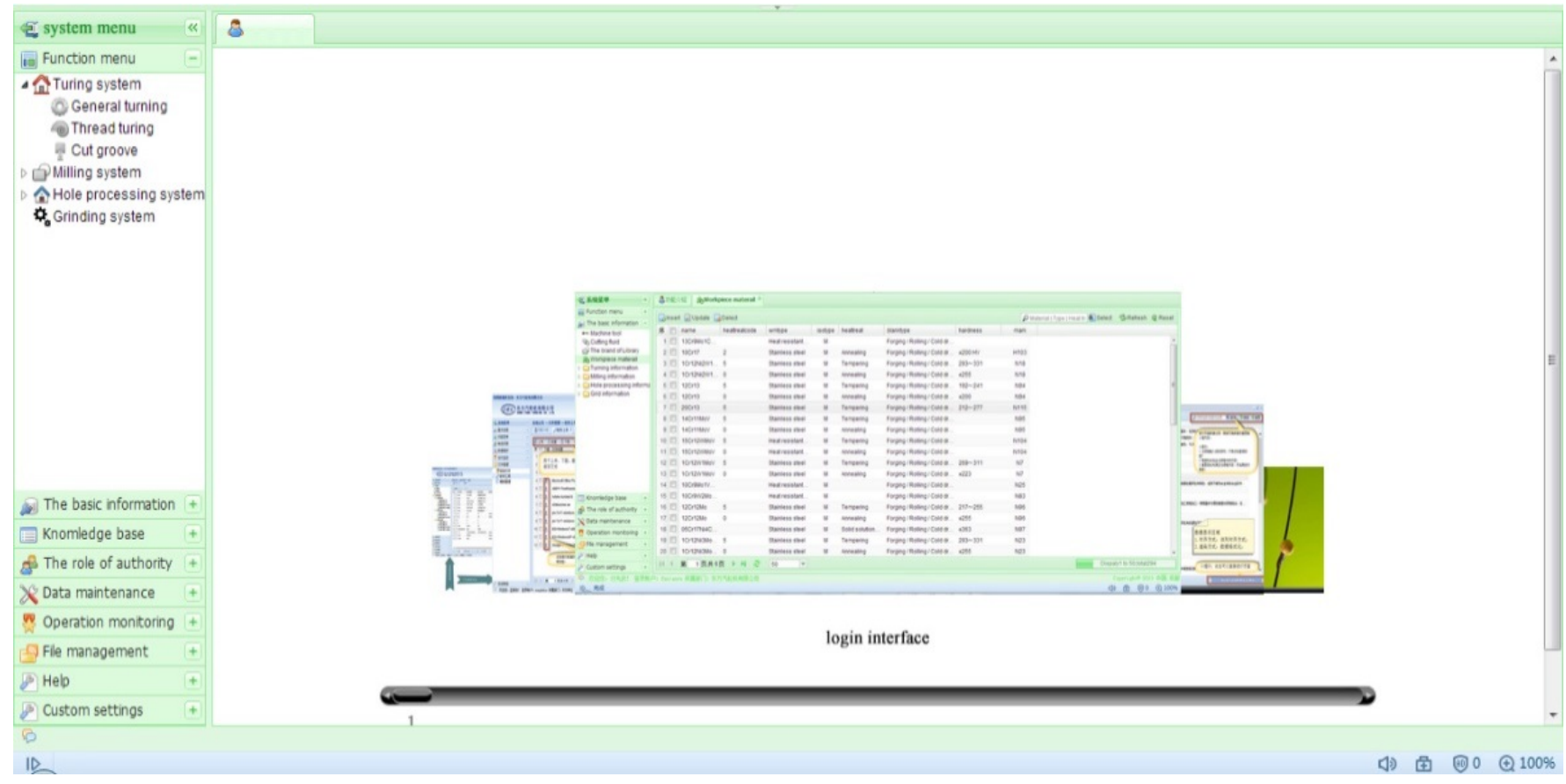

Fig. (6). A Screenshot of boring module.

shaped blade as the shape of the blade, $\mathrm{N}: 0^{\circ}$ as blade angle and $\mathrm{C}: 12=12.7$ as $\mathrm{C}$ type blade corresponding size. Finally, A chose $R=0.4$ as the nose radius. 4 feasible tool schemes were obtained through the dynamic screening, among which CDS marked the optimal scheme to recommend to A. A double clicked the optimal scheme and obtained detailed information about this turning and inserted the appropriate cutting parameters, the matching cutter toolholder and inventory information, which was obtained by the optimization model for tool selection as shown in Fig. (8).

\section{CONCLUSION}

As can be noted, the cutting database system plays an important role in the present manufacture scenario, since more enterprises call for highly intelligent system. The system can help the administrator realize scientific and effective tool management, and help the machine operator select cutting tool and cutting parameters reasonably. Therefore, the cutting database system realized its initial design goal to save cost and improve production efficiency. 


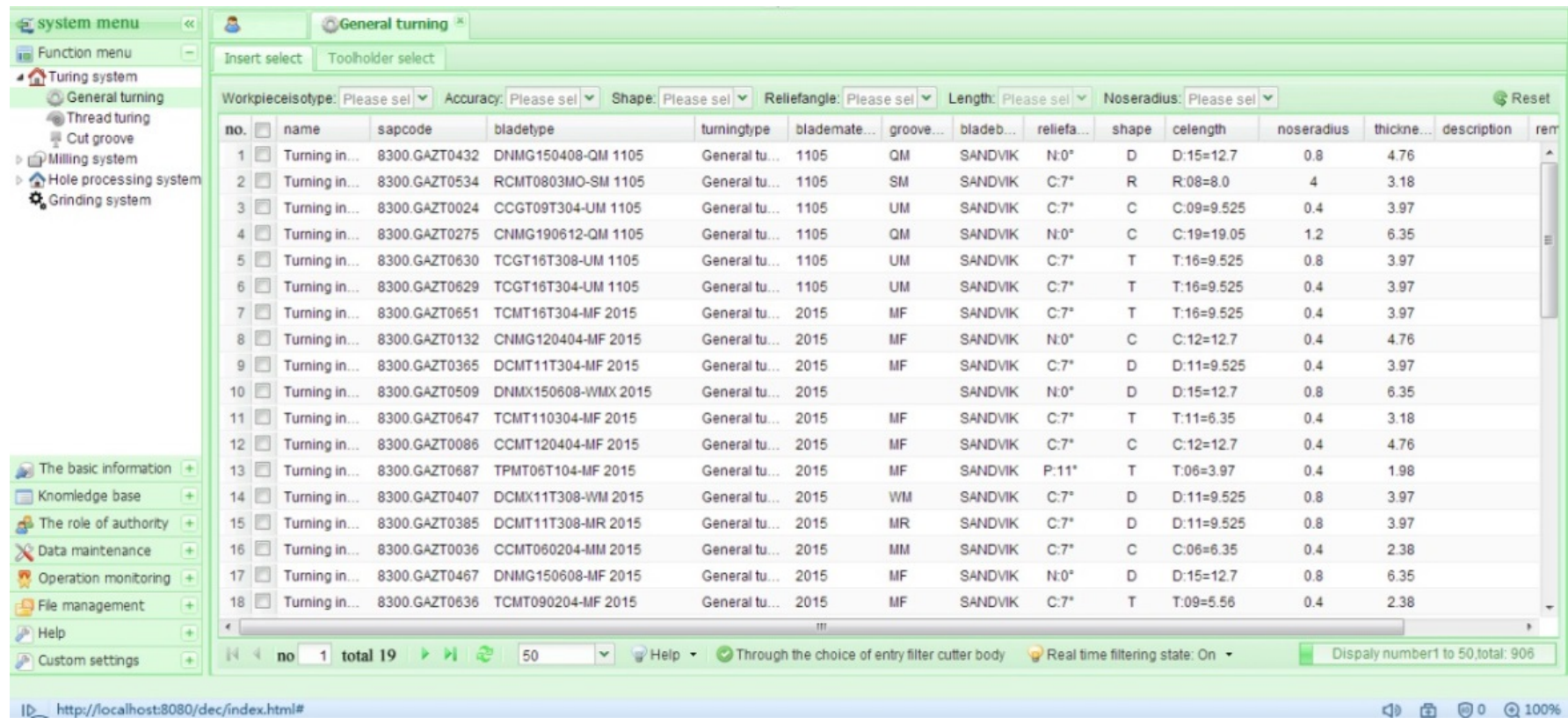

Fig. (7). A Screenshot of the turning working interface.

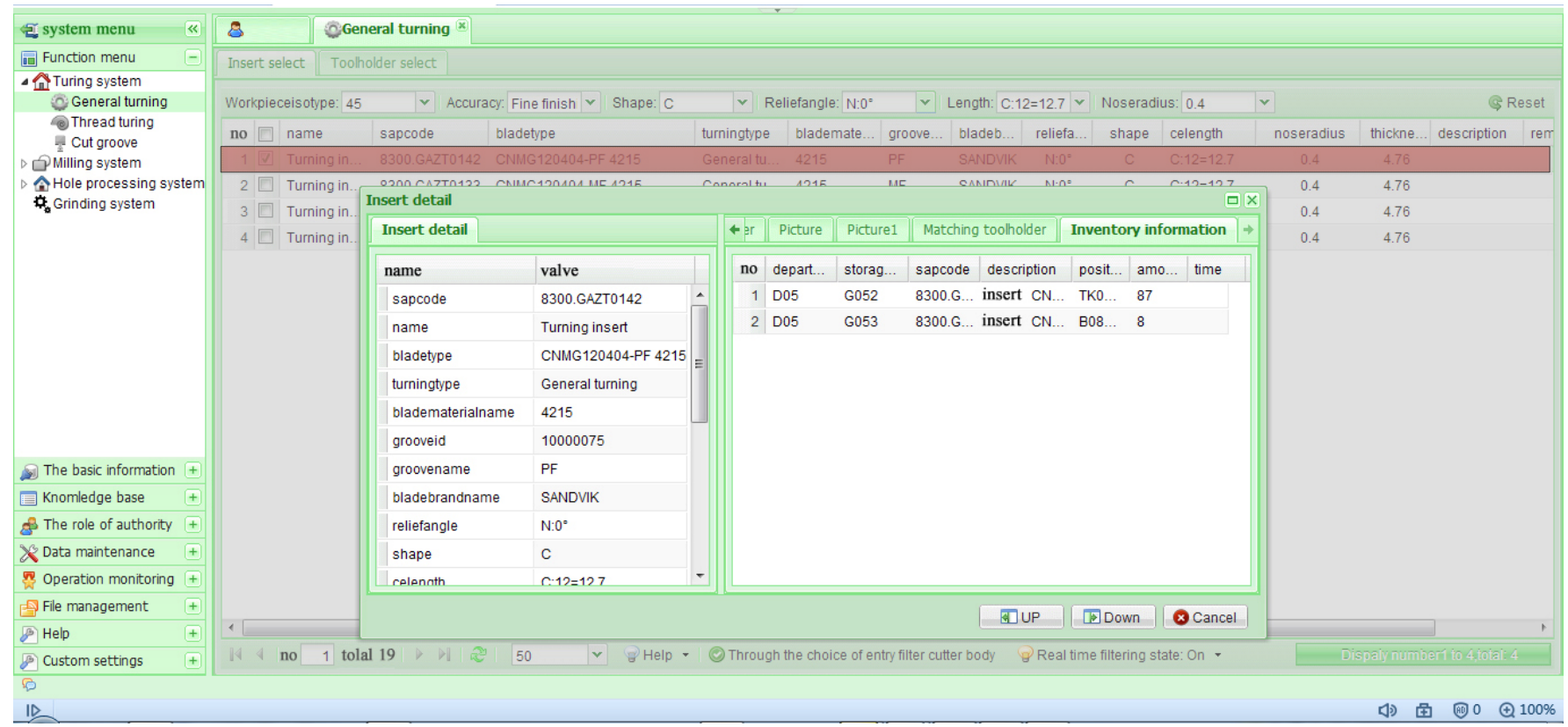

Fig. (8). A Screenshot of the optimal scheme.

However, the system did not perform optimization function for tool choice and cutting parameters, therefore, future improvements in the system work is expected, because it needs a tool selection optimization model and a cutting parameter optimization model.

\section{CONFLICT OF INTEREST}

The authors confirm that this article content has no conflict of interest.

\section{ACKNOWLEDGEMENTS}

This work was supported in part by NSFC (National Natural Science Foundation of China) under Grant
No.51175357, MOST (Ministry of Science and Technology) Works Special of Innovative Approaches under Grant No. 2013IM030500 and Sichuan Province Science and technology support program under Grant No. 2014GZ0114. Gratitude is also extended to the reviewers and the Editor for their valuable comments.

\section{REFERENCES}

[1] M.V. Ribeiro, and N.L. Coppini, "An applied database system for the optimization of cutting conditions and tool selection," Journal of Materials Processing Technology, vol. 92-93, pp. 371-374, 1999.

[2] S. Hinduja, "Determination of the Optimum Tool Set for a Given Batch of Turned Components," CIRP Annals - Manufacturing Technology, vol. 44, no. 1, pp. 445-450, 1995. 
[3] P.G. Maropoulos, and S. Hinduja, "Automatic tool selection for finish turning operations, Proceedings of the Institution of Mechanical Engineers," Part B: Journal of Engineering Manufacture, vol. 204, pp. 43-51, 1990.

[4] P.G. Maropoulos, and S.Hinduja, "Automatic tool selection for rough turning," International Journal of Production Research, vol. 29, no. 6. pp. 1185-1204, 1991

[5] P.G. Maropoulos, and P.A.T. Gill, "Intelligent tool selection:Part I: Logic of the knowledge based module, Proceedings of the Institution of Mechanical Engineers," Part B: Journal of Engineering Manufacture, vol. 209, no. 3, pp. 173-182, 1995.

[6] P.G. Maropoulos, and B. Alamin, "Intelligent tool selection:Part II: Results of the knowledge based module, Proceedings of the Institution of Mechanical Engineers," Part B: Journal of Engineering Manufacture, vol. 209, no. 3, pp. 183-192, 1995.

[7] X.F. Fang, S.W. Zhang, C.Y. Gong, and T.X. Lan, "Study on parameter optimization about NC cutting of marine ship diesel engine and cutting database system," Key Engineering Materials, vol. 392, pp. 392-394, 2009.

[8] C.M. Lo, and S.J. Huang, "Applied object-oriented programming technology to ICT applications development," In: SICE Annual Conference 2010, Proceedings of. IEEE, Taipei, Taiwan: IEEE Xplore, pp. 3336-3339, 2010.

[9] J. Ciurana, G. Arias, and T. Ozel, "Neural network modeling and particle swarm optimization (PSO) of process parameters in pulsed laser micromachining of hardened AISI H13 steel," Materials and Manufacturing Processes, vol. 24, no.3, pp. 358-368, 2009.

[10] R. Pospisil, "Authentication in computer networks and proposal of one-time increase of user permissions," In: Telecommunications and Signal Processing (TSP), 2013 36th International Conference on 2013 Jul 2 IEEE, Rome, Italy, IEEE Xplore, pp.127-132, 2013.

[11] A. Das, and N. Vonada, "Why machines prefer intelligent reasoning from all users?," Amartya sen: because they belong to the human functioning spaces, In: Southeastcon'99. Proceedings, Lexington, KY, USA:IEEE, pp. 173-175, 1999.

(C) Wang et al.; Licensee Bentham Open

This is an open access article licensed under the terms of the Creative Commons Attribution Non-Commercial License (http://creativecommons.org/licenses/by-nc/4.0/) which permits unrestricted, non-commercial use, distribution and reproduction in any medium, provided the work is properly cited. 